\title{
EFICIÊNCIA DE DETERGENTES NA REMOÇÃO DE BIOFILMES DE CEPA DE ESCHERICHIA COLIEM SUPERFÍCIE DE AÇO INOXIDÁVEL
}

\author{
EFFICIENCY OF DETERGENTS IN THE REMOVAL OF ESCHERICHIA COLI \\ BIOFILMS ON STAINLESS STEEL SURFACES
}

Giovana Garcia Fabiano', Raul Gomes Aguera² ${ }^{\star}$, Daniela Biral do Prado.

'UNINGÁ - Centro Universitário Ingá, Maringá, PR, Brasil.

2Universidade Estadual de Maringá, Maringá, PR, Brasil.

*raul1994_gomes@hotmail.com

Recebido em: 15/04/2019; Aceito em: 29/09/2020.

\section{RESUMO}

Escherichia coli é um patógeno associado a doenças transmitidas por alimentos. E. coli pode estar presente na indústria de alimentos através de biofilmes em condições higiênicas inadequadas. $O$ objetivo deste estudo foi avaliar a eficiência de detergentes na remoção de biofilmes de $E$. coli em superfície de aço inoxidável. Os cupons de aço inoxidável AISI 304, acabamento número 4 (dimensões de $8 \mathrm{~mm} \times 8 \mathrm{~mm} \times 1 \mathrm{~mm}$ ) foram imersos assepticamente em microtubos contendo $1 \mathrm{~mL}$ de caldo Mueller Hinton $(\mathrm{MH})$ contaminado com $10^{5} \mathrm{UFC} / \mathrm{mL}$ de E.coli e incubados a $35^{\circ} \mathrm{C}$ por $24 \mathrm{~h}$ para formação do biofilme. Após, cada cupom foi submetido a procedimentos de higienização: limpeza com detergente enzimático por 5 min a temperatura de 40 ${ }^{\circ} \mathrm{C}$ e limpeza com detergente alcalino a $1 \%$ por 5 min a temperatura ambiente. Após as etapas de limpeza, cada cupom foi transferido para microtubo contendo $1 \mathrm{~mL}$ de solução salina a $0,85 \%$ e submetidos a agitação por 2 min para desprendimento do biofilme. Após, foram realizadas as diluições seriadas e o plaqueamento em ágar $(\mathrm{MH})$ para a quantificação das células. Os cupons do controle não receberam agentes de limpeza e suas contagens foram utilizadas para o cálculo do número de reduções decimais devido aos processos de higienização. O tratamento com o detergente enzimático apresentou uma redução de 1,31 log UFC/cm². O detergente alcalino reduziu $\left(3,70 \mathrm{log} \mathrm{UFC} / \mathrm{cm}^{2}\right)$ as contagens de E.coli da superfície de aço inoxidável. Nenhum método de higienização testado removeu totalmente o biofilme microbiano da superfície de aço inoxidável.

Palavras-chave: Aço inoxidável. Biofilme. Detergente alcalino. Detergente enzimático. Escherichia coli.

\section{ABSTRACT}

Escherichia coli is a pathogen associated with foodborne diseases. E. coli may be present in the food industry through biofilms in poor hygienic conditions. The objective of this research was to evaluate the efficiency of detergents for the removal of $E$. coli biofilms from a stainless steel surface. AISI 304, finishing number 4 stainless steel coupons ( $8 \mathrm{~mm} \times 8 \mathrm{~mm} \times 1 \mathrm{~mm}$ dimensions) were 
aseptically immersed in microtubes containing $1 \mathrm{ml}$ of Mueller Hinton broth $(\mathrm{MH})$ contaminated with $10^{5} \mathrm{CFU} / \mathrm{ml} \mathrm{E}$. coli and incubated at $35^{\circ} \mathrm{C}$ for 24 hours for biofilm formation. Then, each coupon was submitted to different procedures of hygiene: cleaning with enzymatic detergent for $5 \mathrm{~min}$ at $40^{\circ} \mathrm{C}$ and cleaning with $1 \%$ alkaline detergent for $5 \mathrm{~min}$ at room temperature. After the cleaning steps, each coupon was transferred to a microtube containing $1 \mathrm{~mL}$ of $0.85 \%$ saline solution and agitated for 2 min to release the biofilm. Afterwards, serial dilutions and agar plating $(\mathrm{MH})$ were performed for the quantification of the detached cells. The control coupons (without detergents) were not given cleaning agents and their counts were used to calculate the number of decimal reduction due to the hygiene processes. The treatment with the enzymatic detergent showed a reduction of $1.31 \mathrm{log}$ CFU / $\mathrm{cm}^{2}$. The alkaline detergent reduced (3.70 log UFC / $\mathrm{cm}^{2}$ ) the $E$. coli counts of the stainless steel surface. No sanitation method tested completely removed the microbial biofilm from the stainless-steel surface.

Keywords: Alkaline detergent. Biofilm. Enzymatic detergent. Escherichia coli. Stainless steel.

\section{INTRODUÇÃO}

A contaminação de alimentos por bactérias patogênicas é um problema de saúde em todas as regiões do mundo (WHO, 2015). Segundo o Sistema de Informações de Agravos e Notificações (SINAN), Escherichia coli foi o principal agente microbiano envolvido em surtos de origem alimentar como diarreia, vômito, náusea, febre, no Brasil de 2007 a 2017 (BRASIL, 2017).

E. coli é incluída no grupo de bactérias Gram-negativas que colonizam o trato gastrointestinal de humanos e animais, que estabelecem uma relação mutuamente benéfica com o hospedeiro. No entanto, análise dos surtos causados através da $E$. coli revela como primeira causa a contaminação fecal de água e alimento devido a saneamentos deficientes, más práticas na fabricação de alimentos e higiene pessoal inadequada dos manipuladores (BRASIL, 2017).

Esse microrganismo pode estar presente na indústria de alimentos formando biofilmes, pois são capazes de aderir e multiplicar na superfície de diversos utensílios industriais que estão em contatos com alimentos, como o vidro e o aço inoxidável (RECH et al., 2016; GOMES et al., 2018).

A expressão biofilme foi criada para descrever a microbiana séssil, ou seja, microrganismos que estão aderidos a superfícies decorrentes da formação de substâncias poliméricas extracelulares, produzindo uma rede gelatinosa que paralisa e preservam as células. A formação de biofilmes ocasiona modificações fenotípicas das células planctônicas, descritas como mecanismos de sobrevivência dos microrganismos em locais com circunstâncias hostis (OLIVEIRA; BRUGNETA; PICCOLI, 2010). O biofilme é composto por carboidratos, fosfolipídios, proteínas, vitaminas e sais minerais, formando uma matriz. Os microrganismos vão se multiplicando gerando uma cultura pura ou vão interagir com outras espécies, consequentemente elevando a defesa.

A matriz de exopolissacarídeos (EPS) excretada tem capacidade de dificultar a entrada de agentes antimicrobianos no biofilme (KASNOWSKI et al., 2010). A formação do biofilme ocorre com as células microbianas planctônicas 
acercando e atingindo a superfície sólida por movimento Browniano, movimento ativo de natação e fluxo hidrodinâmico, assim as bactérias começam a aderir na superfície. A princípio elas estão fixas na superfície de forma reversível, várias voltam para o hábito planctônico por conta da energia de ativação para a dessorção ser baixa, porém uma parte dessas células se transformam irreversíveis, podendo ser devido os apêndices bacterianos como, por exemplo, fímbrias, flagelos, elas conseguem suportar as forças físicas repulsivas da dupla camada elétrica, as bactérias que se aderiram dividem e multiplicam para criam micro- colônias na superfície, sintetizam uma matriz extracelulares que são substancias poliméricas, possibilitando que as micro colônias evoluem, liberando bactérias planctônicas para o ambiente (WANG et al., 2018).

Uma das principais estratégias utilizadas no controle de biofilmes é a higienização, cujos procedimentos consistem no uso combinado de detergentes e sanitizantes. Os detergentes, embora diminuam a carga bacteriana das superfícies, têm como função principal a remoção de resíduos orgânicos e minerais. Além disso, um procedimento de limpeza eficaz deve romper ou dissolver a matriz EPS associada aos biofilmes, de modo que os sanitizantes consigam reduzir os microrganismos deteriorantes e eliminar os patógenos a níveis seguros (PENG et al., 2002; FORSHYTE, 2013).

Os produtos químicos normalmente usados para a limpeza são tensoativos ou produtos alcalinos, com a finalidade de suspender e dissolver resíduos de alimentos, através da diminuição da tensão superficial, emulsionamento de gorduras e desnaturação de proteínas (SIMÕES et al., 2010).

Entretanto, somente a aplicação de detergentes neutros ou alcalinos não são capazes de remover totalmente 0 biofilme, os microrganismos remanescentes podem aderir a outras superfícies e formarem novos biofilmes. Assim, etapas posteriores complementares, como a sanitização com solução clorada são indispensáveis tendo em vista à redução dos microrganismos para níveis aceitáveis (SIMÕES et al., 2010).

Neste contexto, alternativas não convencionais de sanitização e novas ferramentas de controle de biofilmes têm sido estudadas. Uma delas é o detergente enzimático (adição de enzimas a composição) sendo capazes de promover a ruptura da matriz de EPS facilitando a ação do sanitizante sobre os microrganismos, auxiliando na remoção de biofilmes. Entretanto, devido à heterogeneidade de EPS, uma mistura de enzimas pode ser necessária para a remoção desta matriz (SIMÕES et al., 2010).

Assim, o objetivo deste estudo foi avaliar a eficiência de detergente enzimático e alcalino na remoção de biofilmes de cepa padrão de $E$. coli em superfície de aço inoxidável.

\section{MATERIAL E MÉTODOS}

\section{Cultura bacteriana}

A cepa de E. coli (ATCC 25922), obtida do Laboratório de Microbiologia da UNINGÁ foi cultivada em Ágar Mueller Hinton - MHA (Kasvi, São José do 
Pinhais, Paraná, Brasil) e caldo Mueller Hinton - MHB (Kasvi) preparado de acordo com as instruções do fabricante.

\section{Superfície de aço inoxidável}

A formação de biofilmes bacterianos foi avaliada em cupons de aço inoxidável AISI 304, acabamento número 4 (quadrados de $8 \mathrm{~mm} \times 8 \mathrm{~mm} \times 1 \mathrm{~mm}$ ).

Foram avaliados 9 cupons, sendo 3 para o grupo controle (1 para cada experimento), 3 para o grupo de detergente alcalino (1 para cada experimento) e 3 para o grupo de detergente enzimático (1 para cada experimento).

Antes de cada ensaio, os cupons foram lavados com detergente neutro, enxaguados com água destilada, imersos em álcool 70\% (v/v) por 1 hora a temperatura ambiente, enxaguados novamente em água destilada e esterilizados a $121^{\circ} \mathrm{C}$ por $15-20$ minutos (FERNANDES et al., 2014).

\section{Condições experimentais}

Foram preparadas soluções de detergente multienzimático (Rioquímica, São José do Rio Preto, São Paulo, Brasil), e de detergente alcalino (Dicopan L, Sealed-Air, Re-Imagine, São Paulo, Brasil), pH 11-12.

Todos os detergentes foram preparados de acordo com a especificações dos fabricantes, assim seguindo as temperaturas e tempos de imersão recomendados.

\section{Formação de biofilme}

Foi preparada a suspensão bacteriana em solução salina estéril contendo cloreto de sódio a 0,85\% para obter uma turbidez equivalente ao padrão 0,5 da escala de McFarland que contém aproximadamente $1,5 \times 10^{8} \mathrm{UFC} / \mathrm{mL}$. Em seguida, foram realizadas diluições decimais seriadas até a obtenção de suspensão de aproximadamente $1 \times 10^{5} \mathrm{UFC} / \mathrm{mL}$.

Cada cupom de aço inoxidável foi colocado em placa de 24 poços contendo $900 \mu \mathrm{L}$ de MHB e em seguida foi adicionado $100 \mu \mathrm{L}$ da suspensão de E. coli. Em seguida, a placa foi incubada na temperatura de $35^{\circ} \mathrm{C}$ e as análises foram realizadas após 24 horas de formação de biofilme. Posteriormente, cada inoculação, foi realizado um controle da contagem em gotas de acordo com Herigstad, Hamilton e Heersink (2001) de células de E. coli em superfície em ágar MHA a fim de confirmar a concentração inoculada inicialmente do microrganismo. As placas foram incubadas a $35^{\circ} \mathrm{C}$ por $24 \mathrm{~h}$.

\section{Etapas de aplicação do detergente}

Após a formação do biofilme os cupons de aço inoxidável foram retirados do meio de cultura $\mathrm{MH}$ e imediatamente submetidos aos diferentes processos de higienização, conforme as etapas descritas na Tabela 1. 
Tabela 1 - Etapas de higienização aplicadas para a remoção do biofilme de $E$. coli

\begin{tabular}{|c|c|c|}
\hline $\begin{array}{l}\text { Tipo de } \\
\text { higienização }\end{array}$ & Etapas & Condições \\
\hline $\begin{array}{l}\text { Limpeza com } \\
\text { detergente } \\
\text { enzimático } \\
\text { sem agitação }\end{array}$ & $\begin{array}{l}\text { 1. Pré - enxágue } \\
\text { 2. Detergente } \\
\text { 3. Enxágue final }\end{array}$ & $\begin{array}{l}1 \text { min a temperatura ambiente sem } \\
\text { agitação } \\
5 \text { min a } 40{ }^{\circ} \mathrm{C} \text { sem agitação } \\
1 \text { min a temperatura ambiente sem } \\
\text { agitação }\end{array}$ \\
\hline $\begin{array}{l}\text { Limpeza com } \\
\text { detergente } \\
\text { alcalino sem } \\
\text { agitação }\end{array}$ & $\begin{array}{l}\text { 1. Pré - enxágue } \\
\text { 2. Detergente } \\
\text { 3. Enxágue final }\end{array}$ & $\begin{array}{l}1 \text { min a temperatura ambiente sem } \\
\text { agitação } \\
5 \text { min a temperatura ambiente sem } \\
\text { agitação } \\
1 \text { min a temperatura ambiente sem } \\
\text { agitação }\end{array}$ \\
\hline
\end{tabular}

Fonte: os autores.

Em seguida, a realização das etapas de limpeza, cada cupom foi transferido para o microtubo contendo $1,0 \mathrm{~mL}$ de solução salina estéril onde ficou imerso por 1 minuto em repouso, para retirada das células fracamente aderidas ao biofilme. Em seguida, cada cupom foi imerso em 1,0 mL de solução salina estéril e submetidos ao vórtex (2800 rpm) por dois minutos para remoção das células sésseis (FERNANDES et al., 2014).

$\mathrm{Na}$ sequência foi realizado o plaqueamento em gotas (20 uL) de cada diluente em ágar MHA e incubação a $35^{\circ} \mathrm{C}$ por $24 \mathrm{~h}$. Para obtenção dos resultados, as colônias do meio foram quantificadas de acordo com a Equação 1 sugerida por Swanson et al. (1992).

$$
\mathrm{UFC} / \mathrm{cm}^{2}=\frac{(\mathrm{VD} / \mathrm{VA}) \times \mathrm{M} \times \mathrm{D}}{\mathrm{A}}
$$

Onde:

$\mathrm{VD}=$ volume do diluente $(\mathrm{mL})$.

$\mathrm{VA}=$ alíquota utilizada no plaqueamento $(\mathrm{mL})$.

$M=$ média da contagem de unidades formadoras de colônias (UFC) obtida nas placas.

$\mathrm{D}=$ diluição realizada .

$A=$ área $\left(\mathrm{cm}^{2}\right)$ da superfície total avaliada.

Foram realizadas três repetições para cada tratamento.

Os cupons do grupo controle não receberam agentes de limpeza e suas contagens foram utilizadas para o cálculo do número de reduções decimais devido aos processos de higienização. Os resultados das triplicatas foram expressos por média dos valores.

\section{Análise estatística}

Utilizando o programa estatístico BIOESTAT $5.3 \AA$, os valores obtidos e sistematizados foram analisados, utilizou-se o teste t-student para a comparação 
das médias dos resultados obtidos, foi considerado intervalo de confiança de 95\% e significância para o valor de $p \leq 0,05$.

\section{RESULTADOS E DISCUSSÃO}

A quantificação de células aderidas de E. coli na superfície de aço inoxidável e a contagem após o tratamento com o detergente enzimático e detergente alcalino está demonstrado na Tabela 2.

Observa-se que após 24 horas de contato com a superfície de aço inoxidável, a média do número de células sésseis de $E$. coli recuperadas de cupons do grupo controle foi de 8,69 log UFC/cm² e 8,49 log UFC/cm².

Mendonça et al. (2012) avaliaram a formação de biofilme de E. coli O157: H7 em três superfícies diferentes comumente usadas na indústria de alimentos e foi possível observar que na superfície de aço inoxidável AISI 304, acabamento número 4, o biofilme de $E$. coliO157: H7 pode começar a se formar nas primeiras 6 horas de contato.

Ronner e Wong (1993) demonstraram que um mínimo de 5,0-6,0 log UFC $/ \mathrm{cm}^{2}$ é necessário para a formação de biofilme, e menores contagens podem indicar apenas adesão. Portanto, de acordo com os nossos resultados houve formação de biofilme de $E$. coli e isso mostra que se práticas corretas de higiene não forem realizadas essa bactéria é capaz de formar biofilmes.

Rossoni e Gayllarde (2000) notaram diminuição do número de células de E. coli aderidas sobre superfície de aço inoxidável, após tratamento com hipoclorito de sódio. Alternativas não convencionais de sanitização também vêm sendo estudadas como o estudo de Oliveira et al. (2012) constataram que os óleos essenciais da casca de Cymbopogon flexuosus e das folhas de Cinnamomum cassia mostraram-se como potenciais agentes para a produção de sanitizantes para o controle dos biofilmes formados por L. monocytogenes $e$ E. coli enteropatogênica (EPEC).

Já no nosso estudo o detergente com as enzimas na sua composição obtiveram menor redução $\left(1,31 \mathrm{log} U F C / \mathrm{cm}^{2}\right)$ de células sésseis (Figura 1), no entanto diferiu estatisticamente $(p<0.05)$ do grupo controle. Já, o detergente alcalino apresentou maior redução significativa de células sésseis de $E$. coli das superfícies do aço (redução de 3,70 log UFC/cm²) (Figura 2).

Vários estudos têm avaliado a eficácia de detergentes enzimáticos em comparação aos não enzimáticos na limpeza de dispositivos médicos (VICKERY et al. 2004; LUCIANO et al., 2016). Vickery et al. (2004) mostraram que detergentes não enzimáticos foram mais eficazes em relação aos detergentes enzimáticos em biofilmes de E.coli, exibindo uma redução do detergente não enzimático de 4,7 log UFC/ $\mathrm{cm}^{2}$.

Nossos resultados ampliam os achados desses estudos anteriores, pois observa-se que os detergentes não foram capazes de eliminar totalmente o biofilme da superfície de aço inoxidável. 
Figura 1 - Redução de biofilme de E.colina superfície de aço inoxidável após a higienização com o detergente enzimático

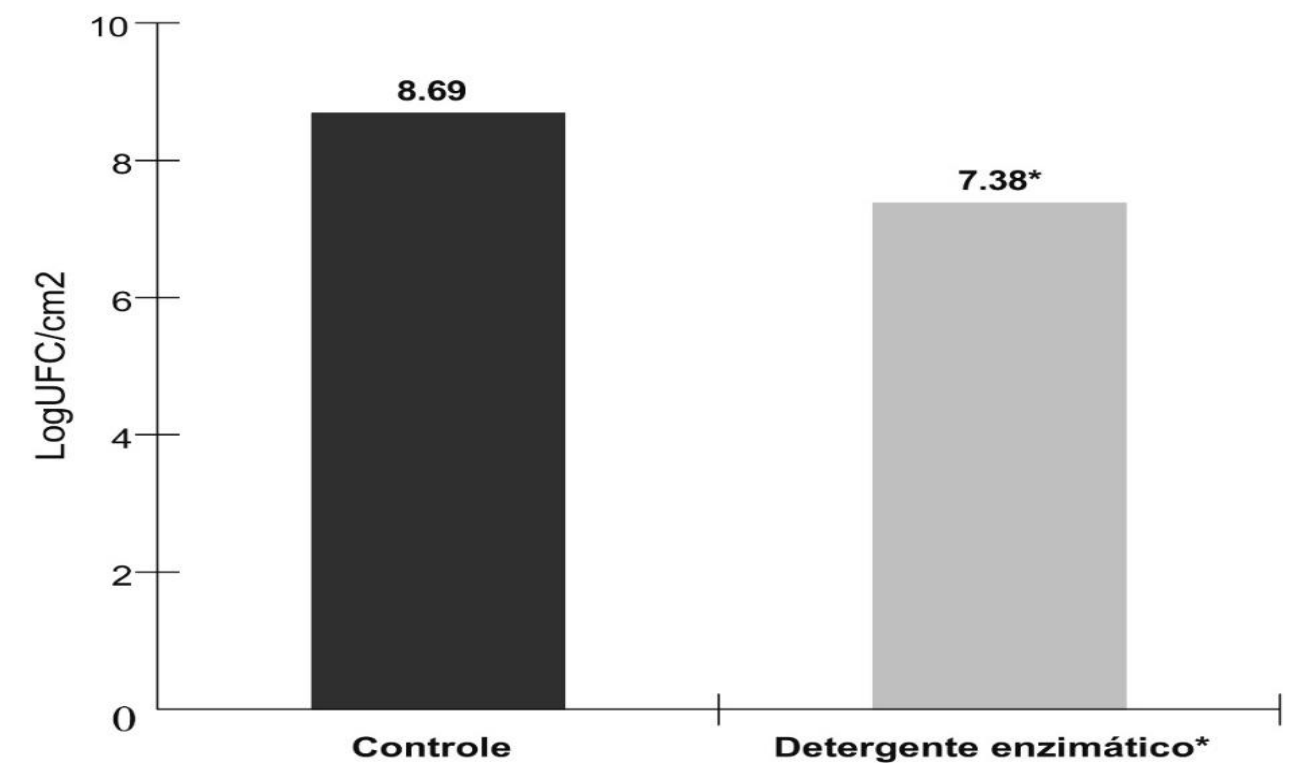

Notas: Grupo controle não recebeu agentes de limpeza. ${ }^{*}$ Representa diferenças significativas $(p<0,05)$ pelo teste t-student.

Fontes: os autores.

Figura 2 - Redução de biofilme de E. coli na superfície de aço inoxidável após a higienização com o detergente alcalino

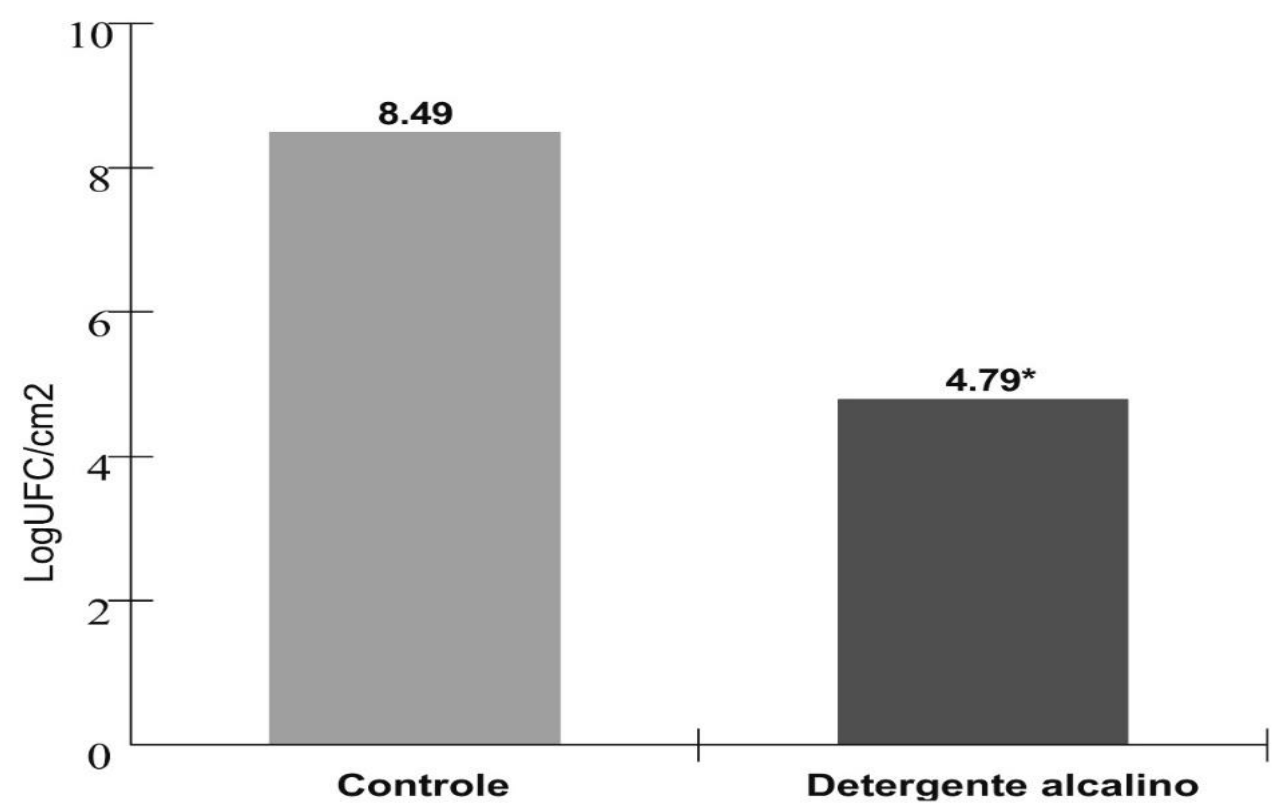

Notas: Grupo controle não recebeu agentes de limpeza. *Representa diferenças significativas $(p<0,05)$ pelo teste t-student.

Fontes: os autores. 
Quando ocorre a remoção incompleta do biofilme, existe a possibilidade que os microrganismos se multipliquem novamente de forma rápida, assim as bactérias conseguem voltar à formação de biofilme logo depois de higienizar 0 local, os microrganismos que sobrevivem à desinfecção geram e produzem uma maior quantidade polímeros extracelulares em resposta aos agentes químicos, além disso, vários pesquisadores apontaram que a higienização possui menos eficácia em microrganismos aderidos quando comparados com as células livres que são planctônicas, sendo fundamentais doses aumentadas (CABEÇA; PIZZOLITTO; PIZZOLITTO; 2012; PEIXOTO et al., 2015).

$O$ detergente deve agir diminuindo a tensão superficial, permitindo uma maior interação da água com o resíduo, promovendo a remoção da superfície à qual está aderido. A solução detergente é usada com o desígnio de separar as sujidades das superfícies que serão higienizadas, mantendo-as dispersas no solvente, evitando que voltem a se depositar (SCHERRER; MARCON, 2016).

A avaliação da eficácia dos desinfetantes é bem complicada, pois existem vários fatores que podem interferir como, a concentração, origem dos resíduos, tipo de microrganismo, superfície de contato e bactérias aderidas em camadas mais internas. A matriz de polímeros funciona como uma barreira adsorvente, diminuindo a quantidade de antimicrobiano, que penetra no biofilme. Sendo difícil conseguir um método capaz de realizar totalmente a desinfecção (OLIVEIRA et al., 2010; PECK et al., 2015; PEIXOTO et al., 2015).

Segundo American Public Health Association (APHA), para ser considerado uma superfície aceitável é necessário o crescimento de $2 \mathrm{UFC} / \mathrm{cm}^{2}$ de mésofilos e a Organização Mundial da Saúde descreve que é até 1,70 log $\mathrm{UFC} / \mathrm{cm}^{2}$ (ANDRADE; PINTO; ROSADO, 2008).

Devido à dificuldade em remover os biofilmes, a remoção dos resíduos deve ser realizada de forma rápida, com o propósito de evitar a formação do biofilme. Ainda se recomenda a limpeza do equipamento ou utensílio, logo após o seu uso pelo fato da adesão pode ocorrer em um intervalo de vinte minutos a duas horas (SCHERRER; MARCON, 2016).

Dentre os diversos procedimentos de higienização incluem o uso de produtos denominados detergentes enzimáticos, que por meio de seus compostos multi-enzimáticos, surfactantes, solubilizantes e álcool isopropílico têm como objetivos proporcionar um processo de limpeza rápido e eficaz (SCHMIDT; YONEKURA; GIL, 2008). Com isso, o resultado do presente estudo sugere que os detergentes enzimáticos precisam de melhor avaliação quanto a sua qualidade e eficiência.

Linhagem selvagem de Streptococcus thermophilus isolada de leite pasteurizado foi avaliada em estudo quanto à adesão em superfície de aço inoxidável e comportamento frente à limpeza e sanificação. A limpeza da superfície de aço inoxidável por detergente alcalino removeu mais que 99,9\% das células aderidas (GÂNDARA; OLIVEIRA, 2000).

MILLEZI (2009) obteve resultados semelhantes realizando tratamentos nos cupons de aço inoxidável com óleos essenciais associados a detergentes alcalinos, para avaliar a eficácia do detergente $\mathrm{NaOH} 1 \%$, foram submetidos a 10 dias em cultivo, na temperatura de $25{ }^{\circ} \mathrm{C}$ e $40 \stackrel{\circ}{\circ}$, o resultado não apresentou eficiência reduzindo apenas dois ciclos de log, nas respectivas temperaturas de $25 \stackrel{\circ}{\circ}\left(2,38 \mathrm{UFC} / \mathrm{cm}^{2}\right)$ e $40 \stackrel{\circ}{\circ}\left(4,52 \mathrm{UFC} / \mathrm{cm}^{2}\right)$. 
Flores (2015) realizou estudo sobre processos de higienização para comparar eficiência do detergente enzimático em relação ao detergente alcalino clorado, a higienização foi feita por placas de corte de polipropileno usadas em processamento de aves, primeiro foi feito a pré-lavagem para remover os resíduos maiores por meio da água a $45^{\circ} \mathrm{C}$, em seguida foi realizado a lavagem com o detergente alcalino na concentração de $3 \%$ por 5 minutos, sendo feito outra vez o enxágue com água em $45^{\circ} \mathrm{C}$, essa técnica também foi realizada com o detergente enzimático, as avaliações foram feitas em triplicatas, depois foi feito a coleta das amostras por meio do teste swab, nenhum dos detergentes alcançaram resultados eficientes, pois a superfície continuou com altos números de mesófilos e aeróbios totais, para o detergente enzimático permaneceu 4,26 log UFC/cm² e o detergente alcalino (3,93 log UFC/cm²).

\section{CONCLUSÃO}

Nenhum dos detergentes analisados foram capazes de remover totalmente o biofilme. $O$ detergente alcalino apresentou ação redutora sobre a $E$. coli na superfície do aço inoxidável apresentando uma eficácia na higienização, mas não houve remoção total do biofilme, sendo necessário um sanitizante em seguida, já o detergente enzimático teve um resultado inferior ao detergente alcalino, porém são necessários mais estudos para verificar a eficácia desses detergentes associada a outros métodos de remoção de biofilme microbiano.

A continuidade desse estudo é indispensável, em busca por produtos que consigam eliminar os microrganismos, proporcionando a segurança dos alimentos, disponibilizando produtos com maior confiabilidade em relação aos alimentos consumidos.

\section{REFERÊNCIAS}

ANDRADE, N. J.; PINTO, C. L. O.; ROSADO, M. S. Controle da higienização na indústria de alimentos. In: ANDRADE, N. J. Higiene na indústria de alimentos: avaliação e controle da adesão e formação de biofilmes bacterianos. São Paulo: Varela, 2008. p. 181-226.

BRASIL. Sistema de Informação de Agravos de Notificação (SINAN). Ministério da Saúde, Secretaria de Vigilância em Saúde, Departamento de Vigilância Epidemiológica, Coordenação Geral de Vigilância das Doenças Transmissíveis, 2016.

CABEÇA, T. K.; PIZZOLITTO, A. C.; PIZZOLITTO, E. L. Activity of disinfectants against foodborne pathogens in suspension and adhered to stainless steel surfaces. Brazilian Journal of Microbiology, v. 43, n. 3, p. 1112-1119, 2012.

FERNANDES, M. S. et al. Enterotoxigenic profile, antimicrobial susceptibility, and biofilm formation of Bacillus cereus isolated from ricotta processing. International Dairy Journal, v. 38, n. 1, p. 16-23, 2014. 
FORSYTHE, S. J. Microbiologia da Segurança de Alimentos, 2. ed., Artmed: Porto Alegre, p. 607, 2013.

GÂNDARA, A. L. N.; OLIVEIRA, J. S. Adesão de linhagem selvagem de Streptococcus thermophilus em superfície de aço inoxidável e efeitos da higienização na sua remoção. Food Science and Technology, v. 20, n. 1, p. 17, 2000.

GOMES, L. C. et al. Impact of modified diamond-like carbon coatings on the spatial organization and disinfection of mixed-biofilms composed of Escherichia coli and Pantoea agglomerans industrial isolates. International journal of food microbiology, v. 277, n. 1, p. 74-82, 2018.

HERIGSTAD, B.; HAMILTON, M.; HEERSINK, J. How to optimize the drop plate method for enumerating bacteria. Journal of microbiological methods, v. 44, n. 2, p. 121-129, 2001.

KASNOWSKI, M. C. et al. Formação de biofilme na indústria de alimentos e métodos de validação de superfícies. Revista Científica Eletrônica de Medicina Veterinária, v. 8, n. 15, p. 1-23, 2010.

KUNIGK, L; ALMEIDA, M. C. B. Action of peracetic acid on Escherichia coli and Staphylococcus aureus in suspension or settled on stainless steel surfaces. Brazilian Journal of Microbiology, v. 32, n. 1, p. 38-41, 2001

LUCIANO, C. C. et al. Evaluation of the ability of different detergents and disinfectants to remove and kill organisms in traditional biofilm. American Journal of Infection Control, v. 44, n. 11, p. 243-249, 2016.

MENDONÇA, R. C. et al. Prediction of Escherichia coli O157:H7 adhesion and potential to form biofilm under experimental conditions. Food Control, v. 23, p. 389-396, 2012.

OLIVEIRA, M. M. M.; BRUGNERA, D. F.; PICCOLI, R. H. Biofilmes microbianos na indústria de alimentos: uma revisão. Revista do Instituto Adolfo Lutz, v. 69, n. 3, p. 277-284, 2010.

OLIVEIRA, M. M. M. et al. Control of planktonic and sessile bacterial cells by essential oils. Food and Bioproducts Processing, v. 90, n. 4, p. 809-818, 2012.

PECK, O. P. W. et al. Application of fluid dynamic gauging in the characterization and removal of biofouling deposits. Heat Transfer Engineering, v. 36, n. 7-8, p. 685-694, 2015.

PEIXOTO, M. M. R. et al. Ação dos desinfetantes sobre a adesão e biofilme consolidado de Staphylococcus spp. Pesquisa Veterinária Brasileira, v. 35, n. 2, p. 105-109, 2015. 
PENG, J. S.; TSAI, W. C.; CHOU, C. C. Inactivation and removal of Bacillus cereus by sanitizer and detergent. International Journal of Food Microbiology, v. 77, n. 1-2, p. 11-18, 2002.

RECH, C. R. et al. Adesão e formação de biofilme de Escherichia coli em poli (tereftalato de etileno) e resistência a sanificantes. Evidência-Interdisciplinar, v. 16, n. 2, p. 113-130, 2017.

ROSSONI, E. M. M.; GAYLARD, C. C. Comparison of sodium hypochlorite and peracetic acid as sanitizing agents for stainless steel food processing surfaces using epifluorescence microscopy. International Journal of Food Microbiology, v. 61, n. 1, p. 81-85, 2000.

SCHERRER, J. V.; MARCON, L. D. N. Formação de biofilme e segurança dos alimentos em serviços de alimentação. Revista da Associação Brasileira de Nutrição, v. 7, n. 2, p. 91-99, 2016.

SCHMIDT, D. R. C.; YONEKURA, C. S. I.; GIL, R. F. Instrumento para avaliação de detergentes enzimáticos. Revista da Escola de Enfermagem da USP, v. 42 , n. 2, p. 282-289, 2008.

SIMÕES, M.; SIMÕES, L. C.; VIEIRA, M. J. A. A review of current and emergent biofilm control strategies. LWT - Food Science and Technology, v. 43, n. 4, p. 573-583, 2010.

SWANSON, K. M. J. et al. Colony count methods. In: VANDERZANT, C.; SPLITTSOESSERD, D. F. Compendium of methods to the microbiological examination of foods 3. ed. Washington, DC: APHA Press, 1992. p. 75-95.

VICKERY K. et al. Removal of biofilm from endoscopes: evaluation of detergent efficiency. American Journal of Infection Control, v. 32, p. 170-176, 2004.

WANG, L. et al. Influence of type-I fimbriae and fluid shear stress on bacterial behavior and multicellular architecture of early Escherichia coli biofilms at singlecell resolution. Applied and Environmental Microbiology, v. 84, n. 6, p. 02343$17,2018$.

WORLD HEALTH ORGANIZATION. Estimates of the global burden of foodborne diseases. Foodborne disease burden epidemiology reference group 20072015. Geneva: World Health Organization, 2015. 255p. 